\title{
Determination of medical abortion success by women and community health volunteers in Nepal using a symptom checklist
}

\author{
Kathryn L. Andersen ${ }^{1 *}$, Mary Fjerstad ${ }^{2}$, Indira Basnett ${ }^{3}$, Shailes Neupane ${ }^{4}$, Valerie Acre ${ }^{1}$, Sharad Sharma ${ }^{3}$ \\ and Emily Jackson ${ }^{5}$
}

\begin{abstract}
Background: We sought to determine if female community health volunteers (FCHVs) and literate women in Nepal can accurately determine success of medical abortion (MA) using a symptom checklist, compared to experienced abortion providers.

Methods: Women undergoing MA, and FCHVs, independently assessed the success of each woman's abortion using an 8-question symptom checklist. Any answers in a red-shaded box indicated that the abortion may not have been successful. Women's/FCHVs' assessments were compared to experienced abortion providers using standard of care.

Results: Women's $(n=1153)$ self-assessment of MA success agreed with abortion providers' determinations $85 \%$ of the time (positive predictive value $=90,95 \% \mathrm{Cl} 88,92$ ); agreement between FCHVs and providers was $82 \%$ (positive predictive value $=90,95 \% \mathrm{Cl} 88,92$ ). Of the 92 women (8\%) requiring uterine evacuation with manual vacuum aspiration ( $n=84,7 \%$ ) or medications $(n=8,0.7 \%), 64 \%$ self-identified as needing additional care; FCHVs identified $61 \%$. However, both women and FCHVs had difficulty recognizing that an answer in a red-shaded box indicated that the abortion may not have been successful. Of the 453 women with a red-shaded box marked, only 35\% of women and $41 \%$ of FCHVs identified the need for additional care.
\end{abstract}

Conclusion: Use of a checklist to determine MA success is a promising strategy, however further refinement of such a tool, particularly for low-literacy settings, is needed before widespread use.

Keywords: Medical abortion, Abortion, Nepal, Self-assessment, Community health volunteers

\section{Background}

Medical abortion (MA) using a combined regimen of mifepristone followed by misoprostol is highly effective with few complications when used to terminate pregnancies up to, and after, 70 days gestation [1-5]. In lowresource settings where access to health care and trained abortion providers is limited, MA can increase the availability of safe abortion, and decrease morbidity and mortality related to unsafe abortion [6]. In Nepal, which continues to face high abortion-related morbidity and

\footnotetext{
* Correspondence: andersenk@ipas.org

${ }^{1}$ Ipas, 300 Market Street, Suite 200, Chapel Hill, NC 27516, USA

Full list of author information is available at the end of the article
}

mortality despite a liberal abortion law and government supported abortion services [7-10], provision of MA up to 63 days gestation has already been extended to include nurses and auxiliary nurse midwives trained as birth attendants, in addition to doctors [11, 12]. We evaluated the ability of a cadre of minimally-trained female community health volunteers (FCHVs) in Nepal and literate Nepali women to determine the success of MA with mifepristone and misoprostol using a checklist. Their assessments were compared to those made by comprehensive abortion care $(\mathrm{CAC})$ trained providers using Nepal's current standard of care.

(c) The Author(s). 2018 Open Access This article is distributed under the terms of the Creative Commons Attribution 4.0 International License (http://creativecommons.org/licenses/by/4.0/), which permits unrestricted use, distribution, and reproduction in any medium, provided you give appropriate credit to the original author(s) and the source, provide a link to the Creative Commons license, and indicate if changes were made. The Creative Commons Public Domain Dedication waiver (http://creativecommons.org/publicdomain/zero/1.0/) applies to the data made available in this article, unless otherwise stated. 


\section{Methods}

This study was conducted in two phases. In the previously published first phase, women and FCHVs used a toolkit consisting of a modified gestational dating wheel and a nine-point checklist of MA contraindications or cautions to assess women's eligibility for MA, compared to experienced CAC-providers using standard of care in Nepal [13]. In the second phase, women and FCHVs used an eight-point checklist to determine if MA had been successful. For purposes of our study, success is defined as MA requiring no additional intervention, such as uterine aspiration or a repeat dose of misoprostol. Women and FCHV responses were compared to experienced CAC-providers. We report the second, success phase of the study in this paper.

\section{Study facilities}

Seven study facilities, public and NGO, in six Nepali districts were purposively selected based on adequate abortion caseload to meet sample size requirements. All study facilities were located in urban centers, drawing patients from the surrounding rural areas.

\section{Study participants}

Three thousand one hundred thirty-one literate women $\geq 16$ years old (the age of consent in Nepal), with a positive pregnancy test, seeking safe abortion at a study facility were enrolled in the phase one, eligibility portion of this study. After completing the phase one study procedures, women received abortion by the method of her choice (uterine aspiration or MA with mifepristone and misoprostol) according to Nepali standard of care. All 1517 women who chose MA were invited to participate in the second, success phase of the study. These women were invited to return for a follow-up visit and evaluation in 2 weeks. Women received 400 Nepali rupees (approximately \$5.20) and a month-supply of iron tablets for their participation in the success study. Those who agreed to participate in the success study but did not return for their 2-week follow-up visit were contacted by phone up to three times to encourage a return visit.

Nepal's FCHVs receive a total of 18 days of training in maternal and child health, including training in early pregnancy identification with urine pregnancy tests; they are a key referral link in their communities to antenatal care, safe abortion, or family planning as appropriate [14]. Literate FCHVs were selected randomly from the six study districts and were posted at each study facility for one to 2 weeks during data collection. Participating FCHVs received a stipend of 3000 Nepali rupees (approximately \$39) per week.

CAC-providers included doctors and staff nurses trained and registered with the Nepal Ministry of Health to provide $\mathrm{CAC}$ with manual vacuum aspiration and
MA. All providers at the included facilities were eligible to participate.

All participants provided written, informed consent to participate.

\section{Sample size}

Previous research indicates that $>90 \%$ of women receiving MA services will have a successful MA, and that the success checklist will have a $90 \%$ specificity to identify an unsuccessful MA [15]. We assumed a precision of 0.1 for both sensitivity (true positive rate) and specificity (true negative rate) of MA success determination, and a two-sided level of significance $(\alpha)$ of 0.5 . Our calculated minimum sample size was 351 women. We continued to recruit beyond our minimum sample size until we had a minimum of 100 women for each public and 50 women for each private facility, and until we had a minimum of 50 women in each gestational age category, by weeks.

\section{Success checklist}

The success checklist (Fig. 1), adapted from Perriera et al. [16], is a series of eight questions assessing bleeding, cramping, and other symptoms following use of MA drugs, designed to determine if women have a continuing pregnancy or ongoing bleeding that would suggest the need for further care from a trained provider. In the real-world setting, if a woman or FCHV marks an answer in a red box on the checklist, the woman would be advised her abortion may not have been successful, and would be prompted to see a health care provider. If no red boxes are marked, the checklist indicates that the woman's abortion was successful.

We tested the checklist for construct validity, and pretested it with Nepali women, FCHVs and CACproviders. We edited the checklist following each round of pretesting; pretesting was considered complete when no further substantive comments were elicited.

\section{Study procedures}

We collected data from September 2013 to March 2014. Each woman received a brief verbal orientation to the checklist, after which she used the checklist to selfdetermine whether or not her abortion had been successful. Demographic information and the woman's assessment of the ease of use of the checklist were also collected. Women's determinations of abortion success were sealed, and women were asked to not share their responses with the FCHV or CAC-provider they would subsequently meet. Next, an FCHV assessed the woman's MA success using the checklist; her assessment was also sealed. Finally, a CAC-provider used local standard of care (typically a history and physical examination, with ultrasound available only when indicated) to assess abortion 


Use this checklist about two weeks after you've taken the first medical abortion tablet to assess whether or
not you need additional medical care.
Success Checklist
Answer each question below by putting a tick in the appropriate box.
\begin{tabular}{|r|l|c|}
\hline \multicolumn{2}{|l|}{} & \multicolumn{2}{l|}{} \\
\hline 1 & Did you have cramping after you took all the medical abortion tablets? & No \\
\hline 2 & $\begin{array}{l}\text { Did you have bleeding at least as heavy as your usual period after you took } \\
\text { all the medical abortion tablets? }\end{array}$ & \\
\hline 3 & $\begin{array}{l}\text { Did you pass blood clots or tissue after you took all the medical abortion } \\
\text { tablets? }\end{array}$ & \\
\hline 4 & Have your pregnancy symptoms gone away? & \\
\hline 5 & Do you think you are still pregnant? & \\
\hline 6 & Are you having heavy bleeding today? & \\
\hline 7 & Do you have a fever today? & \\
\hline 8 & Are you having bad cramping or pain today? & \\
\hline
\end{tabular}
Success Assessment
If you have at least one tick in the red area, see a health care provider. You may still be pregnant or need
additional medical care.
If you do not have any ticks in the red area, your medical abortion was successful. Use contraception to
prevent an unwanted pregnancy.

Fig. 1 MA success checklist. The user answers each question. If any answer is in a red area, the woman may require additional care and should be seen by a provider

success. CAC-providers completed a brief questionnaire documenting their findings.

The Nepal Health Research Council and the Allendale Institutional Review Board in the United States reviewed this study for ethical considerations.

\section{Data analysis}

To assess how well participants understood the success checklist, information entered into the checklist by women and FCHVs was compared to how they ultimately interpreted that information. The assessments of MA success made by women and by FCHVs were compared to those made by CAC-providers using $2 \times 2$ tables. Diagnostic test statistics (positive predictive value [PPV], negative predictive value $[\mathrm{NPV}]$, sensitivity [Sn] and specificity [Sp]) where women/FCHVs correctly identifying success was considered a positive test were generated.

\section{Results}

Over three-quarters (76\%) of the 1517 women enrolled in the phase one, eligibility portion of the study and who chose MA continued into the phase two, success portion of the study $(n=1153$, Table 1$)$. Women who continued into the success portion of the study were more likely to be married than women who did not participate in the second phase (97\% vs $94 \%, p=0.008)$; no other significant demographic differences were found (data not shown).

\section{Comprehension and ease of use of success checklist}

Overall, $74 \%$ of women accurately interpreted their responses on the success checklist. All but two women with no red items marked ( $n=698$ of $700,99.7 \%)$ correctly interpreted their checklist result as 'successful'. However, of the 453 women who marked a red item, 295 (65\%) did not identify that they may require additional care.

FCHVs interpreted the checklist correctly $100 \%$ of the time when no red boxes were marked as indicating a successful abortion, and misidentified women with a red box marked $59 \%$ of the time.

All women and FCHVs (100\%) reported that the success checklist was easy to use. All women (100\%) reported the checklist instructions were clear (yes/no), and

Table 1 Participant sociodemographic data

\begin{tabular}{ll}
\hline & $\begin{array}{l}\text { Participants } \\
n=1153\end{array}$ \\
\hline Age in years, mean (SD) & $27.6(5.4)$ \\
Pregnancies, mean (SD) & $2.8(1.3)$ \\
Some secondary school or higher, $n(\%)$ & $1035(90)$ \\
Married, $n(\%)$ & $1113(97)$ \\
Caste/Ethnicity, n (\%) & \\
Disadvantaged Groups & $351(30)$ \\
Relatively Advantaged & $190(16)$ \\
$\quad$ Upper Caste Groups & $612(53)$ \\
Literacy, n (\%) & $1153(100)$ \\
\hline
\end{tabular}

SD standard deviation

Disadvantaged groups includes dalit, disadvantaged janajaties, disadvantaged non-dalit Terai caste groups, and religious minorities 
$100 \%$ of FCHVs reported that the checklist instructions were either 'very clear' (54\%) or 'somewhat clear' (46\%).

\section{MA success assessment among women, FCHVs, and CAC-providers}

When assessing MA success, women and providers agreed $85 \%$ of the time (Table 2); PPV was 90\% (95\% CI $88,92)$. Providers identified 176 women $(15 \%)$ as potentially requiring additional care. Of these, 84 (7\%) received observation only; the remaining 92 (8\%) received either uterine aspiration $(n=84,7 \%)$ or readministration of medications $(\mathrm{n}=8,0.7 \%)$. Of the 92 women who required additional intervention, $64 \%(n=59$, Table 3$)$ of women themselves perceived that additional care was needed using the success checklist. Of the 33 women who believed that their abortion was successful, six had marked a red item on the checklist. These women misinterpreted their response to the success checklist and should have identified that they needed additional care. The remaining 27 women ( $2 \%$ overall) had no red items marked, and their need for additional care would have been missed if using the checklist alone to determine abortion success.

Agreement for MA success between FCHVs and CACproviders was $82 \%$; PPV was $90 \%$ (95\% CI 88, 92). Of the 92 women requiring additional intervention, FCHVs identified $61 \%(n=56)$. FCHVs incorrectly identified four women who had a red item marked on the Success Checklist as having had a successful abortion; 32 women (3\% overall) had no red items marked and their need for additional care would have been missed if the checklist alone was used.

\section{Discussion}

We found that, when compared to CAC-trained providers using standard of care in Nepal to assess MA success, women using the success checklist agreed with CAC-providers $85 \%$ of the time, with a PPV of $90 \%$. However these results must be interpreted with caution, given the significant difficulty that women had using the checklist. Although women reliably interpreted the checklist when no red items were marked (99.7\%), more than half of the women who marked a red item (65\%) did not realize they might need additional care, and should seek follow-up from a CAC-provider; FCHV results were similar. This is in contrast to earlier evidence indicating that women can accurately determine when their MA is successful using symptom-related questions. Indeed, in studies comparing women's assessments of expulsion to those made by clinicians [16-19] and ultrasound [18], particularly when standardized questions are used $[15,16,19]$, women have repeatedly proven themselves to be nearly as accurate as both. Despite their demonstrated ability to read, it is likely that women and FCHVs in our study did not understand either the checklist instructions, or the checklist items themselves. Indeed, 'literacy' in Nepal, where $43 \%$ of the population is illiterate [20], often indicates the ability to read and write at a basic level; overall reading comprehension in such a population is likely to be more limited and may have affected our findings. This may be different from 'literacy' in the highly literate industrialized nations (United States [14, 15], Scotland [18]) where earlier studies have been conducted. It is also possible that women and FCHVs, regardless of literacy level, required additional orientation to our success checklist to use it effectively. A recent study [21] evaluating the ability of community health workers in Ethiopia, India and South Africa to assess women's eligibility for MA using a similar style of checklist oriented the workers to the checklist in a multi-day workshop. In contrast, the women and FCHVs in our study received a brief introduction,

Table 2 Women's ( $n=1153)$ and FCHVs' $(n=159)$ assessments of MA success using the checklist are compared to CAC providers' $(n=47)$ determinations based on standard of care

\begin{tabular}{|c|c|c|c|c|c|c|c|c|c|c|}
\hline & \multicolumn{2}{|c|}{$\begin{array}{l}\text { Provider assessment MA } \\
\text { successful }\end{array}$} & \multicolumn{2}{|c|}{$\begin{array}{l}\text { Provider assessment } \\
\text { additional care needed }\end{array}$} & \multicolumn{2}{|l|}{ Total } & \multirow{2}{*}{$\begin{array}{l}\text { PPV } \\
\%(95 \%, C l)\end{array}$} & \multirow{2}{*}{$\begin{array}{l}\text { NPV } \\
\%(95 \% \mathrm{Cl})\end{array}$} & \multirow{2}{*}{$\begin{array}{l}\mathrm{Sn} \\
\%(95 \% \mathrm{Cl})\end{array}$} & \multirow{2}{*}{$\begin{array}{l}\mathrm{Sp} \\
\%(95 \% \mathrm{Cl})\end{array}$} \\
\hline & $n$ & $\%^{a}$ & $\mathrm{n}$ & $\%^{a}$ & $\mathrm{n}$ & $\%^{a}$ & & & & \\
\hline Women's Assessment & & & & & & & $90(88,92)$ & $49(41,57)$ & $92(90,93)$ & $44(36,51)$ \\
\hline MA successful & 894 & 78 & 99 & 9 & 993 & 86 & & & & \\
\hline Additional care needed & 81 & 7 & 77 & 7 & 158 & 14 & & & & \\
\hline Total & 975 & 85 & 176 & 15 & $1151^{b}$ & 100 & & & & \\
\hline FCHVs' Assessment & & & & & & & $90(88,92)$ & $41(34,49)$ & $89(87,91)$ & $44(36,51)$ \\
\hline MA successful & 868 & 75 & 99 & 9 & 967 & 84 & & & & \\
\hline Additional care neded & 109 & 9 & 77 & 7 & 186 & 16 & & & & \\
\hline Total & 977 & 85 & 176 & 15 & 1153 & 100 & & & & \\
\hline
\end{tabular}

PPV positive predictive value, NPV negative predictive value, $S n$ sensitivity, $S p$ specificity

${ }^{a}$ Numbers may not add up to $100 \%$ due to rounding

$\mathrm{b}_{2}$ women missing self-assessment of success 
Table 3 Women's and FCHVs' assessments of MA success using the success checklist for the 92 women that CAC-providers determined required additional intervention to complete their abortion (either uterine aspiration or readministration of medications)

\begin{tabular}{lll}
\hline & \multicolumn{2}{c}{ Women receiving additional intervention } \\
\cline { 2 - 3 } & $\mathrm{n}$ & Overall \% \\
\hline Women's Assessment & 33 & 3 \\
MA Successful & 59 & 5 \\
Additional care needed & 92 & 8 \\
Total & 92 & \\
FCHVs' Assessment & 36 & 3 \\
MA Successful & 56 & 5 \\
Additional care needed & 56 & 82 \\
Total & 92 &
\end{tabular}

lasting only several minutes, to the checklist. Increasing comprehension of instructions and questions, reformatting of the checklist, moving away from the red = stop/ green $=$ go coloring scheme, which may not be suggestive enough in this setting, and use of newer technologies, such as a tablet computer, may make the checklist easier to use.

A small proportion of women who believed they had successful abortions based on the success checklist (2\% of women's assessments and 3\% of FCHV's assessments) were determined by $\mathrm{CAC}$-providers to require additional intervention to complete their abortions. These women had marked no red items on their checklists. While it is possible that the checklist did not appropriately capture these as failures, it is also possible that the CACproviders in our study were more conservative than expected in determining abortion success. The CACproviders in our study did not utilize the success checklist when evaluating a patient, and instead relied on their own clinical practice and local standard of care. We found that CAC-providers in our study were more likely to provide additional treatment to women (8\% of women received uterine evacuation with MVA or readministration of medications) than observed in other large MA efficacy trials up to 63 days gestation, where intervention rates are typically between 2 and 3\% [22-24]. Given that an MA follow-up visit is optional in Nepal, it is possible that those women who returned for follow-up in our study were more likely to be experiencing complications, or were more anxious about experiencing complications. It is also possible, given that MA follow-up is not routine in Nepal, that CAC-providers may have been more inclined to intervene in women returning for interim care, a phenomenon that has been suggested in other studies [25]. We did not retrain the CAC-providers included in this study prior to study inception, which may have led them to be more conservative when determining MA success than currently recommended practice. As we considered CAC-providers to be the 'gold standard' for determining success, this is a limitation of our study.

More difficult than determining MA success, both for women and clinicians, has been the identification of those few MA cases where pregnancy is ongoing. As continuing pregnancy after MA is rare, few studies are adequately powered to assess this outcome [26], however a case-control study by Jackson et al. (2012) comparing 53 women with ongoing pregnancies following medical abortion to 53 controls with successful abortions, determined that up to a third of ongoing pregnancies are missed when women's symptoms alone are used to assess completion [27]. While this would affect only a small absolute number of women, given potential teratogenicity of MA drugs and the need for timely uterine evacuation in these cases, the authors suggest that an objective measure of success, such as a urine pregnancy test, is still needed, in addition to report of women's symptoms after MA drug use. Studies in both high [15] and low-resource settings [25] have explored combining a low sensitivity pregnancy test with women's assessment of symptoms to determine MA success and identify rare, unrecognized continuing pregnancies. We did not include such a measure in this study, but this could be a consideration for future work.

Importantly, because of the high success rate of MA with mifepristone and misoprostol, WHO does not recommend routine follow-up after MA using the combined regimen. As provision of MA continues to be expanded to cadres of health care providers with less training [6], and perhaps even to women themselves, a reliable method of determining pregnancy expulsion and rare ongoing pregnancies, will be valuable.

\section{Conclusions}

Although a promising strategy, both literate women and a cadre of minimally trained community health volunteers in Nepal had difficulty correctly using a symptom checklist to determine the success of MA. Refinement of such a tool, particularly for low literacy settings, is needed before widespread use.

\section{Abbreviations}

CAC: Comprehensive abortion care; Cl: Confidence interval; FCHV: Female community health volunteer; MA: Medical abortion; NGO: Non-governmental organization; NPV: Negative predictive value; PPV: Positive predictive value; Sn: Sensitivity; Sp: Specificity

\section{Acknolwedgements}

The authors wish to thank Alyson Hyman and Alexandra Teixiera for their early contributions to the conceptualization of this study. 


\section{Funding}

This study was funded through the operating budget of IPAS; no donors were involved in the analysis or interpretation of findings.

\section{Availability of data and materials}

Due to the sensitive nature of abortion, data is not publicly available but can be provided on request.

\section{Authors' contributions}

KA led study design, analysis, interpretation and writing; MF contributed to design, analysis and interpretation; IB contributed to design, analysis and writing; SN contributed to design, implementation, and interpretation; VA contributed to analysis; SS contributed to design, implementation and interpretation; EJ contributed to analysis, interpretation and writing; all co-authors reviewed and approved the final manuscript.

\section{Authors information}

At the time of this study, Mary Fjerstad, Indira Basnett, and Sharad Sharma were all on staff with Ipas.

\section{Ethics approval and consent to participate}

This study was reviewed by the Allendale Institutional Review Board in the United States and Nepal Health Research Council in Nepal. All participants provided written, informed consent to participate.

\section{Competing interests}

The authors declare that they have no competing interests.

\section{Publisher's Note}

Springer Nature remains neutral with regard to jurisdictional claims in published maps and institutional affiliations.

\section{Author details}

${ }^{1}$ Ipas, 300 Market Street, Suite 200, Chapel Hill, NC 27516, USA. ${ }^{2}$ San Diego, CA, USA. ${ }^{3}$ Kathmandu, Nepal. ${ }^{4}$ Valley Research Group (VaRG), Lalitpur, Nepal. ${ }^{5}$ Los Angeles, CA, USA.

\section{Received: 27 May 2016 Accepted: 30 April 2018}

\section{Published online: 11 May 2018}

\section{References}

1. World Health Organisation Task Force on Post-ovulatory Methods of Fertility Regulation. Termination of pregnancy with reduced doses of mifepristone. BMJ. 1993;307(6903):532-7

2. UK Multicentre Trial. The efficacy and tolerance of mifepristone and prostaglandin in first trimester termination of pregnancy. Br J Obstet Gynaecol 1990, 97(6):480-6.

3. Tang OS, Chan CCW, Ng EHY, Lee SWH, Ho PC. A prospective, randomized, placebo-controlled trial on the use of mifepristone with sublingual or vaginal misoprostol for medical abortions of less than 9 weeks gestation. Hum Reprod. 2003:18(11):2315-8.

4. Ashok PW, Penney GC, Flett GM, Templeton A. An effective regimen for early medical abortion: a report of 2000 consecutive cases. Hum Reprod. 1998;13(10):2962-5

5. Winikoff B, Dzuba IG, Chong E, Goldberg AB, Lichtenberg ES, Ball C, Dean G, Sacks D, Crowden WA, Swica Y. Extending outpatient medical abortion services through 70 days of gestational age. Obstet Gynecol. 2012;120(5): 1070-6.

6. World Health Organization. Health worker roles in providing safe abortion care and post abortion contraception. Geneva: World Health Organization; 2015.

7. World Health Organization. Trends in maternal mortality: 1990 to 2010. In: WHO, UNICEF, UNFPA and the World Bank estimates. Geneva: WHO Press; 2012.

8. Samandari G, Wolf M, Basnett I, Hyman A, Andersen K. Implementation of legal abortion in Nepal: a model for rapid scale-up of high-quality care. Reprod Health. 2012;9(7):1742-4755.

9. Suvedi BK, Pradhan A, Barnett S, Puri M, Chitrakar SR, Poudel P, Sharma S, Hulton L. Nepal maternal mortality and morbidity study 2008/2009: summary of preliminary findings. Ministry of Health: Kathmandu; 2009.
10. Bhandari A, Gordon M, Shakya G. Reducing maternal mortality in Nepal. BJOG. 2011:2:26-30.

11. KC NP, Basnett I, Sharma SK, Bhusal CL, Parajuli RR, Andersen KL. Increasing access to safe abortion services through auxiliary nurse midwives trained as skilled birth attendants. Kathmandu Univ Med J. 2011;9(36):260-6.

12. Puri $M$, Tamang $A$, Shrestha $P$, Joshi $D$. The role of auxiliary nurse-midwives and community health volunteers in expanding access to medical abortion in rural Nepal. Reproductive Health Matters. 2014;22(Supplement 44):94-103.

13. Andersen K, Fjerstad M, Basnett I, Neupane S, Acre V, Sharma SK, Jackson E. Determination of medical abortion eligibility by women and community health volunteers in Nepal: a toolkit evaluation. PLoS One. 2017:12(9): e0178248.

14. Andersen K, Singh A, Shrestha MK, Shah M, Pearson E, Hessini L. Early pregnancy detection by female community health volunteers in Nepal facilitated referral for appropriate reproductive health services. Glob Health Sci Pract. 2013;1(3):372-81.

15. Clark W, Bracken H, Tanehaus J, Schweikert S, Lichtenberg S, Winikoff B. Alternative to a routine follow-up visit for early medical abortion. Obstet Gynecol. 2010;115(2):264-72.

16. Perriera LK, Reeves MF, Chen BA, Hohmann HL, Hayes J, Creinin MD. Feasibility of telephone follow-up after medical abortion. Contraception. 2010:81(2):143-9.

17. Bracken H, Clark W, Lichtenberg ES, Schweikert SM, Tanenhaus J, Barajas A, Alpert L, Winikoff B. Alternatives to routine ultrasound for eligibility assessment prior to early termination of pregnancy with mifepristonemisoprostol. BJOG. 2011:118(1):17-23.

18. Rossi B, Creinin MD, Meyn LA. Ability of the clinician and patient to predict the outcome of mifepristone and misoprostol medical abortion. Contraception. 2004;70(4):313-7.

19. Cameron ST, Glasier A, Dewart H, Johnstone A, Burnside A. Telephone follow-up and self-performed urine pregnancy testing after early medical abortion: a service evaluation. Contraception. 2012;86(1):67-73.

20. State of the World's Children 2015 Country Statistical Information [http:// www.unicef.org/infobycountry/nepal_nepal_statistics.html]

21. Johnston HB, Ganatra B, Nguyen MH, Habib N, Afework MF, Harries J, lyengar K, Moodley J, Lema HY, Constant D, et al. Accuracy of assessment of eligibility for early medical abortion by community health Workers in Ethiopia, India and South Africa. PloS one. 2016;11(1):e0146305.

22. Goldstone P, Michelson J, Williamson E. Early medical abortion using lowdose mifepristone followed by buccal misoprostol: a large Australian observational study. Med J Aust. 2012;197(5):282-6.

23. Gatter M, Cleland K, Nucatola DL. Efficacy and safety of medical abortion using mifepristone and buccal misoprostol through 63 days. Contraception. 2015;91(4):269-73.

24. Chen MJ, Creinin MD. Mifepristone with buccal misoprostol for medical abortion: a systematic review. Obstet Gynecol. 2015;126(1):12-21.

25. lyengar K, Paul M, lyengar SD, Klingberg-Allvin M, Essen B, Bring J, GermzellDanielsson K. Self-assessment of the outcome of early medical abortion versus clinic follow-up in India: a randomised, controlled, non-inferiority trial. Lancet Glob Health. 2015:3(9):e537-3545.

26. Grossman D, Grindlay K. Alternatives to ultrasound for follow-up after medication abortion: a systematic review. Contraception. 2011;83(6):504-10.

27. Jackson AV, Dayananda I, Fortin JM, Fitzmaurice G, Goldberg AB. Can women accurately assess the outcome of medical abortion based on symptoms alone? Contraception. 2012;85(2):192-7.

\section{Ready to submit your research? Choose BMC and benefit from:}

- fast, convenient online submission

- thorough peer review by experienced researchers in your field

- rapid publication on acceptance

- support for research data, including large and complex data types

- gold Open Access which fosters wider collaboration and increased citations

- maximum visibility for your research: over $100 \mathrm{M}$ website views per year

At BMC, research is always in progress.

Learn more biomedcentral.com/submissions 